\title{
The inherent paradox of clinical trials in psychiatry*
}

II Helmchen and B Müller-Oerlinghausen** The Psychiatric Clinic of the Free University, Berlin

The authors sum up the central issue of ethics in the conduct of controlled clinical trials in these two paradoxes: 'first, it is unethical to use treatment the cfficacy of which has not been examined scientificelly; second, it is also unethical to examine the efficacy of treatment scientifically.' In this paper they set out to dcinonstrate how these antithetical statements apply in controlled trials conducted in psychiatric patients. In such trials the problem of obtaining informed consent may be acute, but in these patients giving 'inforined' consent might contribute to a further exacerbation of the illness. Nevcrtheless the problem cannot be craded, and scientific judgments must be applied to treatment for it to be sound and improved for the further benefit of patients. These problems in the case of psychiatric controlled trials are a part of the methodology, and in Germany a new drug law has been drafted to attempt to clarify the issue. The authors briefly discuss its application, and its consequences if such a law were enacted. British psychiatrists have exactly the same problems to face but so far no atteinpts have been madc to establish a legal frainework.

\section{The paradox in medical ethics}

The central issues of ethics in medical treatment can bc summed up by the following paradoxical statements: first, it is unethical to use treatment the efficacy of which has not been examined scientifically; second, it is also unethical to examine the efficacy of treatment scientifically.

It should be clearly understood that the ethical judgment regarding the use of a treatment does not refer to the motivation of the doctor but rather to the efficacy of the therapeutic procedure in the patient. Thus, a passionate intention to help the obsessed patient gave rise to the cruel, mediaeval practice of exorcism', and 'good-heartedness', therapeutic engagement and humanitarian ideology have caused some doctors today 'to relieve the custodial-repressively treated psychiatric patient from the totalitarian institutions'. We know,

* A more academic discussion of the dilemma outlined in this paper is published in the Psychopharmacological Bulletin.

**Professor H. Helmchen; Professor B. Müller-Oerlinghausen, Psychiatrisch Klinik, der Freien Universität, Berlin 19, Nussbaumallee 36 . however, that some of these well meaning theras peutic measures have partly resulted in dependencè increasing misery and criminal exploitation $\vec{t}$ patients. From the ethical point of view it must be asked why these 'therapeutic' measures have no been thoroughly investigated as regards such negative and unexpected consequences before the became widely used ${ }^{2}, 3$.

On the other hand, many presently valuable treatments, such as analytical psychotherapy, malaria therapy and insulin treatment, were invented during the early decades of this centuro and were introduced and applied intensivel without being submitted to appropriate controlle trials. Clinical evidence and possibly comparisons between individuals were regarded as sufficient t $\vec{\theta}$ support a new therapeutic method 4 .

The ethical aspects of a new treatment have always been judged according to the therapeutis resources available at that time. Thus, whem strait jackets were substituted for chains at the beginning of the last century, it was considered to bo humanitarian progress. Similarly, the establishmen? of state mental hospitals was widely praised However, the use of strait jackets is no longe? justified from the ethical point of view and present some people believe that the admission of psychiatric patients to our state institutions objectionable for ethical reasons. We, however believe that the use of a new treatment can be considered as unethical only when its efficacy hà not been tested according to scientific standards i⿱ comparison with all other practicable therapeutis methods.

\section{Ethical problems of 'controlled trials' in psychiatric patients}

The statement that it is unethical to test the efficacy of a treatment in a scientific way is provoca tive although Martini ${ }^{5}$ and his colleagues have already pointed to the indissoluble nature humanity and service toward mankind. Establishin the efficacy of any treatment demands 'controlled trials' according to contemporary standards. The controlled trial is intended to eliminate unspecifit influences by suitable controls. Known objectis influences are excluded by using controls, unknow objective influences by randomization, and sulo jective influences in the patient or the doctor by 
blind technique ${ }^{6}$.

In the following paragraphs we shall focus on the practical consequences of three essentials in controlled trials when applied to psychiatric patients.

\section{THE DESIGN OF THE TRIAL}

A rigidly designed trial is one of the requirements of controlled trials according to contemporary st andards. It requires that the individual needs of a patient - such as the additional drug treatment of insomnia or anxiety - must be sacrificed in favour of the formalized design which excludes additional medication or reduction of dosage. The objective of such a trial is to prove that, for example, the antidepressant drug under investigation possesses fewer side effects or a faster onset of action than the reference drug. Thus, a conflict arises between the ethical obligation to relieve the suffering of the individual patient here and now to the best of our knowledge, and the scientific necessity for an unobjectionable experimental design. But it is also evident that a therapeutic trial which is inconclusive due to a poor design or negligence in carrying out a good desizn is also unethical because (a) it burdens or at least troubles the patient needlessly; (b) it will call for additional experiments unnecessarily and add to the burden of other patients; (c) it prevents the medical community from reaching a clear judgment about the advantages and disadvantages of a new drug as quickly as possible.

The new Cerman drug law (39, I. I) allows the performance of a drug trial only if there is enough evidence for the assumption that the drug to be tested restores the health of the patient or relieves his suffering. This formula secures the therapeutic trial legally; however, it does not resolve the ethical dilemma?. The ethical problem is not whether the patient can be wholly cured by the new treatment, but rather whether - unrestrained by the drug trial design - the patient could have been treated more efficiently.

\section{THE NECESSITY FOR RANDOMIZATION}

Ethical problems can also result from the scientific demand to randomize and to avoid selection. As an example, we may consider the investigation in the United Kingdom (supported by the Medical Research Council) which was performed with great scientific care to determine whether it would be possible to examine with unobjectionable methodology the efficacy of several psychotherapeutic procedures $^{8}$. As it turned out, some investigators did not keep to the rule of randomization in dealing with patients who, according to the personal experience of the investigators, could be helped only by analytical psychotherapy. These investigators came to the conclusion that because of ethical considerations it was not feasible to prove the efficacy of psychotherapy in a controlled trial according to the methodological design they had agreed upon previously (see also ${ }^{9}$ ).
'Since ethical issues may have played a decisive roie in determining the negative outcome of the study, the investigating team considered this problem in more detail. Not unexpectedly, it appeared that the issues are complex and operate at a number of different levels. Where uncertainty about the effectiveness of a certain treatment is widely shared by all those concerned in its use, then there will be little difficulty in setting up properly controlled studies for its evaluation. But this is not the case with psychotherapy. Some patients belicve that this is the only form of treatment that will help them (and, in contrast to drug trials, the nature of the treatment they, in fact, receive cannot be concealed from them). Some general practitioners and general psychiatrists believe that certain patients require psychotherapy, although this conclusion cannot at present be based on firm evidence. The investigating team itself must, of necessity, contain members who are more troubled by ethical problems than other members of the team, who see the study simply as an attempt to evaluate a treatment the effectiveness of which has $n$ t $t$ yet been established. So it seems that cooperative controlled studies of psychotherapy are particularly vulnerable to limitations imposed by ethical considerations. These difficulties cannot easily be overcome, since where ethical issues are concerned, there can be no easy compromise; once an ethical objection has been raised, the limitations thereby imposed have to be accepted, even by those who do not accept the force of the objection. However, these problems are not confined to psychotherapy trials's.

Ethical considerations have led to the exclusion of suicidal patients from some trials with new antidepressant drugs, or at least from the placebowashout period. In other cases, patients might not have been admitted to a study because it was assumed that the fixed dosage regime might be ineffective or poorly tolerated ${ }^{10}$. Such a procedure may satisfy the treating physician but it can result in a specific selection of patients, eg, those suffering from only moderate or light depression, and thus make it impossible to judge critically the efficacy of the new drug. Such an allegedly ethical selection of patients could also prevent the discovery of an improved treatment of the most severely ill and suicidal depressive patients. This situation must be considered as unethical because the final evaluation of a new drug for its therapeutic usefulness must comprise a clear statement about the entire scope of possible indications. By the same token, it seems doubtful whether a restriction of a drug trial only to 'therapy-resistant depressions' can be justified on ethical grounds.

\section{INFORMED CONSENT}

A very serious ethical and legal problem can arise with regard to the use of 'informed consent' in therapeutic trials. This also can be illustrated by

\section{.}


two paradoxical statements: first, it is unethical to perform a therapeutic trial without the informed consent of the patient; second it is also unethical to perform a therapeutic trial with informed consent.

The first statement seems to be self evident, but it should nevertheless provoke some reflections about the inconstancy of ethical standards. For example, there is no evidence to suggest that the 26 hospitalized acute schizophrenics in whom Klaesi used 'sleep' therapy for the first time in 1920, or the catatonic schizophrenic subjected by Cerletti and Bini to the first treatment with electroshock in 1938, had been informed about the experimental quality of the new therapy or were even asked for their consent ${ }^{4}$. None of these early investigators would have considered informed consent to be a necessary prerequisite for his experiment; rather they judged their experiments as ethically justified by the expected therapeutic benefit for mankind. In our times, however, the demand of society for scientific progress competes more and more with the modern, liberal consciousness of the individual's right to self determination ${ }^{11}$. It also seems well founded that this right to self determination should be explicitly defended in view of the immanent dangers resulting from the explosive increase in experimental investigations in human subjects and also because of the demand for more therapeutic trials which will be the inevitable consequence of the new German drug law 7, 12, 13.

The second statement of the paradox raising ethical objections against the informed consent of the patient may be less evident. This statement can be clarified, however, by considering the specific methodology as well as the therapeutic customs of psychiatry.

The specific scientific methodology in psychiatry derives from the fact that the effect of treatment might be related to the specific personality of the doctor as well as to that of the patient. The difficulties in investigating these influences of personality on the therapeutic effect arise from the complexity of the human individual and the obscure relationship between the biological milieu interne and the social milieu externe. Therefore, when testing the efficacy of a new psychiatric treatment, the therapist must be the object of the trial as a specific therapeutic factor or his unspecific influence must be reliably controlled. The same applies to the influences resulting from the subjectivity of the patient. Thus, it is evident that the blind technique plays an important role in scientific trials of new therapeutic procedures in psychiatry. The fact that the double-blind technique has its own methodological limitations, and that under certain conditions its results are not superior to those of an open trial ${ }^{14}, 15$, does not invalidate the requirements for the use of the double-blind technique. It may be mentioned in this connexion that the use of the video technique in an open trial allows a blind evaluation with certain limitations 16 m We cannot in this paper go into the ethical problems of using the double-blind technique for? prophylactic trials $17,18,19$. The crucial point is that many investigations of new psychiatric therapies cannot dispense with the blind technique

However, little is known about the influence of fully or partially informing the patient on the validity of blind trials. 'Full information' includes not only information of the expected effects and risks of the drug to be tested, but also the fact that the patient will be subjected to an experiment which is based on randomization and the blindw technique*. A serious problem can arise if the reference drug in a double-blind trial is a placebo since many patients might refuse to consent to thetrial. In addition, those patients who do consent to the trial represent a biased sample, and the results? obtained from them will not be representative of the entire group of patients with the particular? illness under investigation but only of those patients who will consent to a therapeutic trial. A long as the influence of the information remains obscure and its scientific relevance doubtful, fully informing the patient may be of doubtful import $=$ ance from an ethical point of view. Here, it is to beo noted that ever since the first edition of Martini' ș methodology 21 in 1947 , it has been regarded as 20 necessary prerequisite of a controlled therapeutie trial that the patient be unaware of the experimentap character of that therapy. The German Pharmacon logical Association has supported this fundamentao postulate when commenting on the first draft of the new German drug law ${ }^{22,23,24}$. The ethica foundation of experimental work will probably not be improved if this scientific-ethical principle is renounced. It seems to be much better under some circumstances to burden the investigator with the full responsibility that a clinical trial is un: objectionable from an ethical point of view ${ }^{25}$ than to obtain the 'informed consent' of the patient. If help is needed in making this decision, it could be found in a peer committee whose members must have sufficient inside knowledge of the psychiatric reality (see also reference 26 ). Quoting Ingelfinger $27 \frac{8}{2}$ 'The subject's only real protection, the public as well as the medical profession must recognizes depends on the conscience and compassion of the investigator and his peers'.

The requirement of 'informed consent' in general treatment could also lead to ethical problems. For example, the psychiatrist would have toํำ decide at the beginning of a course of analyticab psychotherapy whether the patient should be informed about the danger of his suicide during

*It is striking that the statements concerning 'ethics' in the latest Food and Drugs Administration 'guidelines for psychotropic drugs' do not even touch upon this problem ${ }^{18}$. 
treatment or of exacerbation of his illness; at the beginning of treatment using behaviour therapy about the risks of a shift of symptoms; at the beginning of a course of treatment with antidepressive drugs about the probability of a druginduced agranulocytosis. The physician might prefer to consider that not informing the patient was ethically justified since such information might bring damage to him rather than benefit. Withholding information seems to be not only ethically justified but even necessary if, for example, the hopeless feelings of a depressed patient would be reinforced by the information that antidepressive activity can be observed only in approximately 60 per cent of treated patients, or if the retarded depressive patient is unable to decide whether or not he will consent to the trial, in spite of all the information given to him.

In many cases the real question might be whether the patient is able to give informed consent at all. A patient who suffers from delusions of guilt and believes that he should be punished and is not worthy of receiving a new drug treatment cannot in fact give his 'informed consent'. According to the law, the guardian of the patient should be asked for permission in such a case. However, it appears to be unethical to install a guardian only in order to perform a drug trial because the social consequences of guardianship may be more injurious to the patient than the very small risk of injury caused by the drug trial. Keeping strictly to the law can thus lead to unethical behaviour. This suggests that the researcher should not be completely relieved of the necessity to make his own ethical decisions in this situation $^{20,} 27$.

\section{Legal rules or improved ethical standards?}

Several individual aims are in conflict: I) the individual's right to self determination must be protected despite the demand of society for scientific progress, and 2) the necessity to perform controlled trials goes against the obligation to treat the individual patient in an optimal way. These problems cannot be solved by making one idea superior to another but only by reaching the best compromise between the individual aims, all of them having their special ethical justification. Such compromises will not be facilitated by precise legal rules, for the more detailed the rules that exist, the greater become the following risks.

I) The conditions under which scientific trials must be performed could become so different from the reality of treatment that the results of such trials will lack validity. To quote Lasagna, 'Certainly most drugs would not be applied under the conditions of a double-blind trial, including informed consent, hospitalization, avoiding additional medication, prescription by experts, etc' 29 .
2) Legal rules for every detail of a clinical trial might finally be ignored or shirked in an uncontrolled way. This could lead to poorly planned drug trials and make it very difficult to judge the scientific value of the experimental results.

3) Clinical trials might be regarded by clinicians or investigators as too troublesome and even antitherapeutic, or economic considerations might cause pharmaceutical companies to refuse to support or stimulate such trials. Thus, there is a danger that disproportionate demands of governmental institutions might raise the costs of developing a new product so excessively that industry would be forced to concentrate their scientific efforts on only a few and popular lines of pharmacological treatments and to cut off or considerably reduce fundamental scientific research on completely new drugs ${ }^{30}, 1,31$. In this respect the 'drug lag', ie, the divergence between the development and introduction of new and effective drugs between the USA and other countries, eg, Great Britain, should be considered as a warning symptom. To quote Wardell (1974), '... contrary to general belief, the early stages of new drug investigation are extremely safe... Rather than continually raising the animal and human premarketing hurdles, society might benefit more from ascertaining intensifying postmarketing surveillance. The latter approach appears to be a major difference in practice between the current drug regulatory system in the United States and Britain'31.

4) It could be foreseen that detailed legal rules with all their bureaucratic and administrative consequences would shift responsibility for the drug trials from the treating and investigating physician to the government or the pharmaceutical companies. Cavers (1972) pointed out that 'questions of professional ethics fall under the broader rubric of professional responsibility, and the effort to establish effective governmental controls over new drugs may in time produce a major shift in the responsibility for carrying out drug investigation' 32 . The responsibility should remain with the investigator not only to maintain his competence but also in order to develop and to strengthen his ethical consciousness. Professionals in the medical field should make every effort to introduce their own ethical standards, as they arise from modern medical technology, into the shaping of new legal controls in therapeutics 33,34 .

It might be considered unethical to demand 'informed consent' from a psychiatric patient, and to obey rigidly precise rules in therapeutics might result in unethical behaviour. While this may be true, the ethical demands for protecting the rights of the individual as well as of society must also be carefully complied with. In this regard a medical education which tries to make the physician sensitive and able to decide upon ethical questions is called for 35,36 . As a general conclusion we would 
suggest that medical education and postgraduate training should develop a doctor's competence to perceive where and when and to what extent his professional or scientific activities imply ethical problems and to find solutions which demonstrate his qualifications and competence ${ }^{37}$. Such qualification may sometimes also be expressed by the fact that the investigator would demand the advice of experienced colleagues. It seems necessary to guarantee to the public the ethical competence of physicians. The eventual embodiment in law of the increasing public concern over immoral and illegal behaviour of physicians involved in medical research can be best counteracted by establishing rigid professional cuntrol although it does not appear to be very helpful or practicable to transfer decisions about every psychiatric treatment to a peer committee ${ }^{38}$. However, in all cases where 'informed consent' cannot be demanded from the patient, a group of competent persons should be informed of the design of the planned trial. 'Competent persons' does not necessarily mean only members of the medical profession, but also includes nurses, psychulogists, or clergymen - but, only those of them who have experience in treating or helping psychiatric patients.

Novel and urgent ethical questions always arise when the quality or quantity of new scientific discoveries has reached a certain limit. If, in this situation, the ability to perceive ethical problems and to decide on them in a competent way does not keep up with scientific progress, then a moratorium will be needed in order that scientific progress does not get out of our ethical control ${ }^{34}$. Similar concepts are reing discussed at present in other scientific disciplines, eg, in the field of human genetics ${ }^{40}$.

\section{References}

'Jetter, D (1970). Der Humanitätsgedanke in der Psychiatrie. Das ärztliche Gesprüch nr I2, 5-15 Tropon, Köln.

'Brill, H (1974). Die psychiatrische Versorgung in den USA. Bisheriges Ergebnis eines Experimentes. Vortrag auf dem Kongre $\beta$ der DGPN.

Wing, J K (1975). Die Evaluation gemeindenaher psychiatrischer Dienste, Archiv für Psychiatric 1!nd Nereen Krankheiten, 220, 245-254.

${ }^{+}$Helmchen, H (1973). Insulinbehandlung, Schlafoehandlung, Psychochirurgie, Elektroschock. in Müller, C (Hrsgb.) Lexikon der Psychiatrie. Springer, Berlin - Heidelberg.

${ }^{5}$ Martini, P, Oberhoffer, G und Welte, E (1968). Methodenlehre der therapeutisch-klinischen Forschung. 4. Auflage. Springer, Heidelberg - New York.

'Uberla, K (1972). Nachweis der Unbedenklichkeit (Unschädlichkeit) und der therapeutischen Wirksamkeit. Der Standpunkt des Statistikers. Therapiewoche, 22, 2046-2052.

'Entwurf eines Gesetzes zur Neuordnung des Arznei- mittelrechts. Die Pharmagentische Industric, 36m I-60 (I974).

Candy, J, Balfour, F H G, Cawley, R H, Hildebrand Ș. H P, Malan, D H, Marks, I M, and Wilson, J (I972) A feasibility study for a controlled trial of forma psychotherapy. Psychological Medicine, 2, 345 36́z

"Hoffmann, S O, und Gebhardt, R (1973). Möglich $\frac{\bar{O}}{\bar{n}}$ keiten der Kontrolle psychotherapeutische Ergebnisse. Praxis der Psychotherapie, 18, $2412.52 \AA$

"Lauritsen, B J, and Madsen, H (1974). A multinationalő double-blind trial with a new antidepressantmaprotiline (Ludiomil) and amitriptyline. ActP psychiatrica Pcandinavica. 50, 192-20I.

"In Der Beeck, $M$, und Wuttke, H (1969). Grundlage und Grenzein der ärztlichen Aufklärungspflicht Nervenarst, 40, 587583.

'Freund, P A (Ed.) (1972). Experimentation with human subjects. G Allen and Unwin, London.

${ }^{13}$ Hasskarl, H, and Kleinsorge, $\mathrm{H}$ (1974). Arzneimittel prüfung, Arzneimittelrecht. G Fischer, Stuttgart. 은

${ }^{1}$ Helmchen, H (1969). Praktische Probleme der klinischen Doppelblindprüfung von Antidepressiva Arzneimittel Forschung (Drug Research), $19 \mathrm{D}^{\circ}$ $88 \mathrm{I}-882$.

${ }^{15}$ Schou, M (1974). Heutiger Stand der Lithium Rezidivprophylaxe bei endogenen afiektiven Erk $=$ rankungen. Nervenarzt 45, 397-418.

${ }^{1}$ 'Renfordt, E (1974). Audiovisuelle Methoden in deç Psychiatrie. Nervenarzt, 45, 505509.

${ }^{1}$ 'Baastrup, P C, Poulsen, J C, Schou, M, and Thomsen, (1970). Prophylactic lithium: double blind dis continuation in manic-depressive and recurrento depressive disorders. Lancet, 2, 326333

FDA guidelines for psychotropic drugs (draft - Jun 1974). Psychopharmacological Bulletin, ro, 70.

Hcimchen, H, and Müller-Oerlinghausen, B (1974) Längsschnittprofile der Wirkungen von Psycho pharmaka aus kilnisch-methodologischer Sicht Arzneim-Forsch, 24, $976-980$.

"Ayd, F J (Jr), and Blackwell, B (1971). The scientifi and ethical problems of psychotropic drug researc: in prison volunteers: a consensus communication Psy'chopharmacological Bulletin, 7, 35-38.

"Martini, P (1947). Methodenlehre der therapeutisch klinischen Forschung. Springer, Berlin Güttingen?

Arbeitsgemeinschaft planmäßiger Professoren füp Pharmakologie und Toxikologie. Schreiben vonn. I8.2.1974 an den Bundesminister für Jugend心 Familie und Gesundheit.

${ }^{2}$ Deutsche Pharmakologische Gesellschaft. Schreibero vom 5.2.74 an das Bundesministerium für Jugend Familie und Gesundheit.

${ }^{2+}$ Maxwell, C (1973). Clinical research for all. Cambridge Medical Publications, Cambridge.

${ }^{5}$ Brill, H (1974). Bundesverband zur AMG-Novelle@ Stellungnahme der Pharmazeutischen Industrie zum Regierungsentwurf (Stand 17.7.74) eine Gesetzes zur Neuordnung des Arzneimittelrechts. Zweites Arzneimittelgesetz. Die Pharmazeutische Industrie, 36, 627-632.

${ }^{26}$ Richardson, J (1970). Richtlinien für Forschung suntersuchungen am Menschen. Schweizerischo 
Akademie der Medizinischen Wissenschaften, Basel.

${ }^{27}$ Ingelfinger, F J (1972). Informed (but uneducated) consent. New England Fournal of Medicine. 287, 466. In Cooper, I S, Riklan, M, and Snider, R S (Eds): The cerebellum, epilepsy, and behaviour. Plenum Press, New York - London.

${ }^{28}$ Smith, H C (1974). Some ethical considerations of cerebellar stimulation as an innovative therapy in humans. In Cooper, I S, Riklan, M, and Snider, R S (Eds): The cerebellum, epilepsy, and behaviour. Plenum Press, New York - London.

${ }^{29}$ Lasagna, L (1973). Die Beweisführung in der pharmakologischen Forschung. Triangel 11, 145-152.

${ }^{30}$ Heimann, $H$ (1975). Administrative und juristische Probleme der Psychopharmakologie. Arzneimittel Forschung (Drug Research) (In press)

${ }^{31}$ Wardell, W M (1974). Therapeutic implications of the drug lag. Clinical Pharmacological Therapy, 15, 73-96.

${ }^{32}$ Cavers, D F (1972). The legal control of the clinical investigation of drugs: some political, economic and social questions. In Freund, $P$ A (Ed.): Experimentation with human subjects. G Allen and Unwin, London pp 225-246.
${ }^{33}$ Rieke, L V (1973). Some major guides for laws. In Williams, $\mathrm{R} \mathrm{H}$ (Ed): To live and to die: When, why and how? Springer, Heidelberg - New York.

${ }^{34}$ Wolstenholme, G E W, and O'Connor, M (Eds.): Ethics in medical progress. CIBA Foundation Symposium. J A Churchill Ltd. London 1966.

${ }^{35}$ Richardson, J (1972). Morale in clinical medicine. British fournal of Psychiatry, 120, 593-599.

${ }^{36}$ Veatch, R M, and Gaylin, W (1972). Teaching medical ethics: An experimental program. Fournal of Medical Education, 47, 779-785.

${ }^{37}$ Helmchen, H, and Müller-Oerlinghausen, B (1973). Psychopharmakologie und psychiatrische Facharztweiterbildung. Nervenarzt, 44, 204-206.

${ }^{38}$ Halleck, S L (1974). Legal and ethical aspects of behaviour control. American fournal of Psychiatry, 131, 38I-385.

${ }^{39}$ Swazey, J P and Fox, R C (1972). The clinical moratorium: a case study of mitral valve surgery. In Freund, P A (Ed): Experimentation with human subjects. G Allen and Unwin, London, pp 31 5-357.

${ }^{40}$ Baltimore, D, Berg, P, Boyer, H W, Cohen, S N, Davis, R W, Hogness, D S, Nathans, D, Roblin, R, Watson, J D, Weissman, S, and Zinder N D (1974). NAS ban on plasmid engineering. Nature (Lond.) 250, 175 . 